\title{
Sustainable deployment of
}

environmental management systems for higher education institutions: challenges and limitations

Juliette M. O'Keeffe

Edward Simpson

M. Ehsan Jorat

Margi Vilnay

This is the Accepted Manuscript of a book chapter published in University partnerships for sustainable development

O'Keeffe, J.M., Simpson, E., Jorat, M.E. \& Vilnay, M. (2020) 'Sustainable deployment of environmental management systems for higher education institutions: challenges and limitations'. In: E. Sengupta, P. Blessinger \& T.S. Yamin (eds.). University partnerships for sustainable development. Emerald, Bingley, pp. 81-99.

The final published version is available from doi: 10.1108/S2055-364120200000020010 


\title{
Sustainable deployment of environmental management systems for higher education institutions: challenges and limitations
}

\author{
Juliette M. O’Keeffe, Edward Simpson, M. Ehsan Jorat ${ }^{1}$, Margi Vilnay
}

\begin{abstract}
Higher Education Institutions (HEIs) face unique barriers to implementation of environmental management systems (EMSs) compared to the private sector, where formal EMS approaches such as ISO 14001 are widely used. HEIs across the world have tended to adopt structured EMSs through less formal methods or apply bespoke approaches. Organisational factors specific to HEIs impact on their ability to implement and sustain formal EMS approaches, including different organisational profiles compared to the private sector. This study finds that considerations of the key actors, existing organisational structures, governance and leadership, and resistance to change are important areas to consider in the implementation of an EMS within an HEI. UK HEIs are used as a case study to examine the relationship between EMS uptake and performance, and identify trends towards adoption of various types of systems. A trend towards adoption of more formalised EMS approaches amongst UK HEIs contradicts the suggestion from literature that less formal approaches may be more suitable. The study challenges the assumption that formal approaches to environmental management provide the gold standard EMS, suggesting that alternative standards may be more suitable in the context of the unique organisational structures and key barriers to EMS implementation faced by HEIs.
\end{abstract}

Keywords: higher education institutions, environmental management systems, key actors, organisational structure

\section{Introduction}

The process of managing specific areas of strategic responsibility such as quality systems and environmental impacts are complex and typically bureaucratic. Organisations have therefore sought to apply management systems to simplify the management process, drive collection of results and observe progress against targets (Esquer-Peralta, Velazquez, \& Munguia, 2008), often developing around the process known as the Deming Circle, Shewart cycle or the Plan Do Check Act (PDCA) approach (Oung, 2013). These approaches are typical in complying with recognised International Organisation for Standardisation (ISO) management systems such as ISO 9001: Quality Management, ISO 14001: Environmental Management and the Occupational Health and Safety Advisory Service standard, OHSAS 18001. These systems impact upon operational guidelines and procedures for identifying, measuring, and recording key information and acting to achieve targets or key performance indicators.

In the area of environmental management, the ISO 14001 system is a widely known environmental management system (EMS) applied in the private sector. In Europe there are over 100,000 ISO 14001 certified sites, and 10,000 sites certified to the similar EcoManagement and Audit Scheme (EMAS) ranging from small businesses to multi-national corporations, to public bodies (ISO, 2015; EC, 2014). Factors influencing the uptake of formal EMS approaches such as ISO 14001 are diverse, and can include cultural, environmental and

\footnotetext{
${ }^{1}$ Corresponding author: e.jorat@abertay.ac.uk
} 
economic factors (Bracke and Albrecht, 2007) although there is evidence that internal organisational factors are more influential than external drivers (Psomas, Fotopoulos, \& Kafetzopoulos, 2011). These factors affect the approaches to establishing a framework by which organisations can manage their environmental impacts as an EMS influences policy objectives, allocation of responsibilities and resources, operational procedures, performance reviews, and goals for continual improvement (Spellerberg, Buchan, \& Englefield, 2004).

Organisations using the ISO 14001 standard are currently transitioning from the 2004 standards to the ISO14001:2015, which were fully adopted in September 2018. The new standard requires greater demonstration that environmental policy and objectives align to organisational strategy, that the organisation considers aspects and impacts in a wider sense, for example upstream impacts (e.g. purchasing choices) and wider impacts of the environment on company operations (e.g. adaptation to climate change) are considered. It has been argued that the updated ISO14001 standard is moving towards the more rigorous EMAS system, and is more difficult to achieve (Szyszja \& Matuszak-Flejszmann, 2015) with better environmental gains over the longer term (Testa et al., 2014). These formal systems also typically include aspects and impacts that are deemed to be measurable and manageable, and may exclude some of the wider environmental and sustainability aspects with less tangible metrics.

In the higher education sector, ISO 14001 and EMAS are rated more highly over less formal EMS approaches in University league tables such as the UK Green League (People and Planet, 2016). The connection between EMS implementation such as ISO14001, and improved performance is not always clear, and whether EMS implementation leads to improved performance may be dependent upon the organisational goals, culture and other drivers (Nawrocka \& Parker, 2009). The increased uptake of formal EMSs in HEIs signals a move towards positive advancement in environmental performance, but organisational characteristics can impact the success of any system, and the degree of positive change that can be achieved (Tinsley, 2012).

This chapter examines the relationship between organisational structure and EMS implementation to explore how the success of EMSs can be affected by the involvement of key actors and organisational decision-making structures within the HEI. We reflect on how these may affect the successful implementation and long-term sustainability of an EMS within HEIs, and use UK HEIs as a case study to examine approaches to environmental management and the trend towards adoption of more formalised EMS approaches.

\section{Environmental management in the HEI sector}

Interest in sustainability for HEIs became more visible with the signing of various international environmental declarations. Examples include the Talloires Declaration 1990, committing the signatories to provide leadership and support on environmental protection issues, and the Halifax Declaration 1991, emphasising the role of HEIs in providing leadership on sustainable development (Bekessy, Samson, \& Clarkson, 2007; Marinho, Gonçalves, \& Kiperstok, 2014; ULSF, 2014). Despite interest and promotion, the adoption of formalised EMS has been limited until recently. In 2012, Disterheft, Caeiro, and Azeiteiro reported that of approximately 4000 HEIs in the EU 27 countries (EC, 2013) only 47 universities in Europe were pursuing the implementation of a formal EMS on their campus and of these, only 6 were in the UK accounting for only $3 \%$ of the 163 UK HEIs at that time. In the USA, a survey of 275 HEIs found that $38 \%$ identified themselves as having a structured and comprehensive EMS but only 
$2 \%$ of those surveyed indicated they had achieved formal ISO 14001 certification with many North American HEIs surveyed pursuing informal EMS approaches, with no common structure being used across the sector (Clarke \& Kouri, 2009). Alternatives to the formality of ISO 14001 and EMAS tend to be systems with staged approaches to environmental management implementation such as the Eco-Campus system and the IEMA Acorn Scheme (BS 8555). Across the EU, semi-formal systems employed in HEIs include Eco-Campus (UK), Oficina Eco-Campus (Spain), and RUMBA (Switzerland), and many other regional systems such as Green Dragon (Wales) (Disterheft et al., 2012).

Environmental management has not traditionally been viewed as a mainstream activity amongst HEIs (Carpenter and Meehan, 2002) with many HEIs identifying as having a role to play in providing practical leadership to graduates, and leading on the wider acceptance and awareness of sustainability in society (Altan, 2010; Spellerberg et al., 2004; Jones, 2012; Spirovski et al., 2012). Drivers for implementation of environmental management systems in HEIs are diverse and include social and environmental awareness, league tables, reputation and financial and business improvement (Spellerberg et al., 2004; Clarke and Kouri, 2009; Altan, 2010; Disterheft et al., 2012; Spirovski et al., 2012; Ortas et al., 2013; Wen-hsin Hsu and Wang, 2013; NIEA, 2009). League tables and statutory reporting are influencing HEIs to provide evidence of achieving environmental performance to maintain or increase their standing relative to others, driving a shift towards more formalised systems focussed on operational aspects. This suggests a move from the traditional social and environmental awareness drivers (Altan, 2010; Spellerberg et al., 2004; Jones, 2012; Spirovski et al., 2012; Disterheft et al., 2012) to those more focussed on business and reputation management including resource consumption as a financial consideration (Jones, 2012; Ortas, Burritt, \& Moneva, 2013; Wenhsin Hsu \& Wang, 2013; NIEA, 2009). While this may suit private sector businesses, key features of HEIs suggest that this trend carries some risk.

\section{The importance of the organisational profile to EMS success}

\subsection{Key actors}

Successful implementation of an EMS is linked to the key actors in the process (Oung, 2013). Applying this to the HEI sector, organisations must take account of the unique key actor groups that exist within an HEI. Institutions define these differently but typically include some or all of the following groups:

- Academics, researchers, students, senior management, senate, technical and support staff and the local community (Lozano, 2006b; Clarke and Kouri, 2009; Saleh, Kamarulzaman, Hashim, \& Hashim, 2011).

These groups are in addition to key actor groups found in most organisations, including administrative and operations staff. The degree to which each of the key actor groups are engaged in the development and implementation of an EMS can impact the success of the EMS. The mechanism of delivery (e.g. top down vs. participatory approaches) can also influence success.

\subsubsection{Top Down approaches}

Top-down influence comes from senior administrative or operational management based on strategic organisational priorities, requiring top-level support as an essential pre-requisite for success (Bero et al., 2012; Rocha et al., 2007). Top-down influence can reduce the time needed 
to implement change, allocate appropriate resources, encourage a more systematic approach to be applied and can help to mainstream sustainability (Bekessy et al., 2007; Esquer-Peralta et al., 2008; Sambasivan \& Fei, 2008). Top-down drivers for environmental management address operational aspects (e.g. reduced energy consumption) and reputational improvement (linked to league table performance), and thus result in more formalised systems that align with key management priorities of achieving these associated financial or reputational benefits. Within the structure of HEIs, top-down approaches can exclude other key actor groups and affected by changes in management, competing resources or changing priorities. Top-down punitive initiatives do not motivate staff to comply or participate in the process (Jones, 2012; EsquerPeralta et al., 2008) and are successful when staff and student groups participate in the development process.

\subsubsection{Bottom Up}

Bottom-up or student led approaches most commonly employ awareness raising techniques providing enthusiasm and political drivers to garner support from management for environmental actions as this group is not in a position to directly make changes to policy or working practices (Brinkhurst, Rose, Maurice, \& Ackerman, 2011). A strong student government can be effective in lobbying HEI management for change for ad-hoc or short-lived initiatives, acting as an external force for change rather than a collaborative and cooperative approach, and can at times become adversarial (Brinkhurst et al., 2011; Jones, 2012). Conflicts can arise when priority areas for action are not the same for the student body compared to management leading to a limitation in the cultural shift needed to achieve some environmental actions (Bekessy et al., 2007). The lack of consistent longer-term student leadership due to annual elections for leaders results in the lack of long-term leaders of initiatives (Spellerberg et al., 2004; Jones, 2012).

Despite these challenges, student groups are important key actors, agents of change and influencers within any HEI. Spira, Tappeser, and Meyer, (2013) found that exclusion of student groups in environmental management could result in systems that are focussed largely on operational aspects, and demonstrate less integration of sustainability concepts throughout the campus. For example at the University of Greenwich, student groups initiated lobbying for greater action on sustainability on the campus, which led to the University taking action and rising from near the bottom of the Green League table in 2008, to the top in 2012. A formal EMS, verified to ISO14001 standard was implemented but this approach limited the ability of student groups to be involved in environmental management, limiting the essential cultural change needed to become embedded across the whole institution (Spira et al., 2013).

\subsubsection{Middle Out}

For an EMS to be a powerful tool for driving improved environmental performance and a paradigm shift, it must be delivered in combination with participation (Disterheft et al., 2012). For HEIs, a simultaneous top-down/bottom-up approach is needed (Lozano, 2006b; Clarke \& Kouri, 2009; Beringer, 2007).

Many of the actions required to improve environmental performance across the institution will not be technical in nature, but instead have a socio-cultural element (Button, 2008). Individuals most able to influence the socio-cultural elements of environmental management will be those involved closely with the largest actor groups - staff and students. This favours a middle-out approach, where key actors involved in coordinating sustainability approaches are staff 
members that interact across management, students, and other groups including estates and facilities, support services and others (Brinkhurst et al., 2011) and aligns with participatory strategies for semi-formal or alternative EMSs rather than formal EMSs. These groups have a deep understanding of university functions, have a depth of technical and academic expertise that can be directed towards problem solving and ideas generation, providing a connection between the student groups, senior management and administration.

Where management support is absent, faculty or staff-led approaches can face challenges such as feelings of lack of empowerment to affect change within the institution where time or resources to carry out initiatives are not sanctioned. This can suppress entrepreneurial efforts leading to lack of initiative and innovation amongst the middle groups (Brinkhurst et al., 2011). Bekessy et al. (2007) identified problems that were encountered at RMIT University in Australia in the implementation and maintenance of greening projects on campus. The failure to sustain initiatives was caused by factors such as management disinterest, limited resources, lack of direct access to management and decision making, and no authority to delegate tasks.

Linking the key actor groups to choice of EMS approach can help identify the approaches that may or may not be appropriate for a given institution. Formal systems that are implemented without the inclusion of other key actor groups may provide limited ability for long-term sustainable change to be affected.

\subsection{Organisational and decision making structures}

Factors such as organisational structure, decision-making processes and culture of change management can be important to success (Tinsley, 2012). Organisational and decision-making structures in HEIs are different to private sector organisations, with differing implications of features that affect EMS success.

\subsubsection{Coordination and organisational structure}

Barriers to implementation of sustainability initiatives on campuses include a lack of coordination of efforts (Clarke \& Kouri, 2009, Saleh et al., 2011), something which an EMS can help to address by defining key roles such as sustainability or environmental managers (Clarke \& Kouri, 2009; Oung, 2013; Lozano, 2006b; Bekessy et al., 2007). These roles provide a link between all internal stakeholder groups and decision makers and can oversee implementation through environmental steering groups, maintain momentum through integrated participation and ensure that policy commitments are delivered (Oung, 2013). Decision-making structures that are too complex and bureaucratic put the EMS at a disadvantage (Esquer-Peralta et al., 2008); leading to barriers to change where environmental and sustainability issues may only be discussed in fora focussed on operational aspects. Where sustainability efforts are located within estates departments (campus facilities departments) the focus is directed towards actions linked to cost savings, including mainly energy and waste management (Jones, 2012). This approach favours formal management systems where auditable evidence is relatively straightforward to collate and report and actions can be delivered directly by the department.

Sustainability efforts delivered solely by estates departments can develop a disconnect from the wider university population and exclude bottom-up or middle-out led initiatives by students, the community and academic staff (Jones, 2012). The move towards greater uptake of ISO 14001 amongst UK HEIs suggests that there is a shift towards more operations based 
approaches to environmental management rather than a shift towards systems that encompass sustainability more broadly. The challenges and difficulties with achieving formal EMS accreditation across the complex organisation and decision-making structures of HEIs can limit the units of assessment to those that are easy to manage and measure. Changing perceptions, habits, and behaviours, can potentially have more impact and a greater return on investment than physical measures (Spirovski et al., 2012). Formalised systems that focus on operational issues only may risk exclusion of creative ideas for improvements and may not engage the wider university population that could be included in positive change.

\subsubsection{Change management}

The attitude of individuals towards change is one of the primary barriers to implementation, therefore organisations ill-equipped to address attitudes to change are at a disadvantage (Esquer-Peralta et al., 2008). Resistance to change can take the form of apathy and procrastination as a result of the affected parties not valuing or agreeing with the change programme. Maurer's three levels of resistance to change (Lozano, 2006b) include:

$\circ$ resistance to the idea stemming from lack of understanding or knowledge

$\circ$ resistance based on deeper issues associated with fear of losing control or position

- deeply embedded resistance associated with trust, cultural issues, differences in deep-rooted opinions or values or past conflicts related to change

Sources of resistance can arise from staff who perceive their roles have been treated as insignificant and environmental and sustainability actions are considered to result in more costs than benefits (Saleh et al., 2011). In particular where people feel disconnected from the approaches or actions being implemented through a general lack of awareness and understanding (Disterheft et al., 2012), lack of awareness (Palmer, 2004) or poor communication of the business case (Saleh et al., 2011). Involvement of groups across the organisation can assist in overcoming some of the barriers when combined with recognition and celebration of campus efforts towards sustainability, building support and credibility throughout the university community (Brinkhurst et al., 2011). In addition, maintaining regular two-way communication on the meaningful impacts that have been achieved assists in maintaining momentum, and helps to mainstream sustainability into everyday activities and operations.

Resistance to change based on deeper issues is more difficult to overcome when impacted parties feel loss of control, power or position (Lozano, 2006b). The solution requires a process of identifying individuals most impacted by loss of control or power as a result of the change process and attempting to manage their role within the process through collaborative consultation and inclusion in planning. Permission to be involved along with encouragement to contribute to decision making can empower and motivate individuals (Brinkhurst et al., 2011). Resolving deep-rooted resistance issues requires the fostering of cultural change across the organisation (Lozano, 2006b). Semi-formal or informal systems that engage bottom-up and middle-out initiatives are more likely to lead to acceptance of the change, where it is encouraged by peers or influential individuals within the organisation. Maintaining momentum is important to emphasising that management is serious about change. The use of evidencebased case studies can be used to demonstrate the value in change to the resisters, and motivate them to adopt changes (Esquer-Peralta et al., 2008). 


\subsection{Case Study: Adoption of EMS approaches across the UK HEI sector}

\subsection{EMS uptake in UK HEIs}

The UK has approximately 160 HEIs that report to the Higher Education Statistics Agency (HESA), as a producer of Official Statistics on a range of indicators such as income, student numbers, size of the estate and a wide range of environmental performance criteria. In 2012/13, HESA began reporting on the presence and type of EMS used by HEIs. Prior to this, data was collected on the presence of an environmental policy, environmental auditing, and the number of environmental staff. No details on the presence or type of EMS was collected. Today environmental data collected by HESA is presented separately from finance, student and staff data, and has gained a higher profile across HEIs submitting returns to HESA. A review of this data for UK HEIs was carried out for the 2012/13 to 2016/17 reporting tables.

Table 1 presents key summary data derived from the HESA tables (HESA 2017a-d). In 2012/13, 85 UK HEIs indicated use of an EMS, compared to 100 in 2016/17. There is a notable change in the type of EMS applied. Since reporting of EMS type began in 2012/13 the number of HEIs applying an EMS certified to ISO 14001 has more than doubled, accounting for about $38 \%$ of UK HEIs in 2016/17. The number of HEIs using alternative, EMS approaches including Eco Campus (Bronze, Silver, Gold, Platinum), Green Dragon, Acorn BS8555 and bespoke systems has decreased over the five year period from 51 to 39. The data indicates a trend towards wider adoption of the formal EMS approach of ISO14001 in preference to alternative systems.

Table 1. EMS implementation across UK HEIs 2012-2015

\begin{tabular}{l|c|c|c|c|c|}
\hline & $2012 / 13$ & $2013 / 14$ & $2014 / 15$ & $2015 / 16$ & $2016 / 17$ \\
\hline Number of HEIs reporting & 158 & 159 & 160 & 160 & 159 \\
\hline Number of UK HEIs with an EMS & 85 & 88 & 91 & 97 & 100 \\
\hline $\begin{array}{l}\text { Number of UK HEIs implementing } \\
\text { ISO 14001 }\end{array}$ & 29 & 37 & 47 & 58 & 61 \\
\hline $\begin{array}{l}\text { Number of UK HEIs implementing } \\
\text { alternative system }\end{array}$ & 56 & 51 & 44 & 39 & 39 \\
\hline Number of UK HEIs with no EMS & $\begin{array}{c}58, \\
(15 \text { n.d.) }\end{array}$ & $\begin{array}{c}57, \\
(14 \text { n.d. })\end{array}$ & $\begin{array}{c}54, \\
(15 \\
\text { n.d.) }\end{array}$ & $\begin{array}{c}49, \\
(14 \text { n.d.) }\end{array}$ & (13 n.d.) \\
\hline
\end{tabular}

n.d. $=$ no data

\subsection{EMS adoption and environmental performance}

HESA data was interrogated further to identify if the move towards adoption of ISO14001 was also associated with improved performance for selected key indicator criteria (energy consumption, water consumption, and waste production as well as non-resource based indicator \{Fair Trade accreditation\}). Summary data for all HEIs indicates that between 2012/13 and 2015/16 energy consumption and carbon emissions have, on average, decreased across the sector, however, water consumption has increased and waste production has remained relatively static. This data will be affected by a range of complex factors, including fluctuating student numbers and changes to course and research portfolios across institutions, as well as generic factors affecting all institutions such as temperature fluctuations affecting winter 
heating or summer air conditioning demand. Benchmarking across institutions is therefore challenging. Indicators such as Fair Trade accreditation can be examined as independent of student number, programme portfolio or weather. Across the sector, there has been a decrease in the number of HEIs with Fair Trade accreditation from 114 in 2012/13 to 90 in 2016/17. In order to examine the relationship between EMS implementation and performance, HESA figures were examined in greater detail to identify whether differences could be observed between groups of HEIs with EMSs certified to ISO 14001, compared to those with alternative systems, or no EMS at all. Using indicators of average annual energy consumption, average annual water consumption, annual waste production and presence of Fair Trade accreditation, we can identify some differences in the groups (Fig. 1-4).

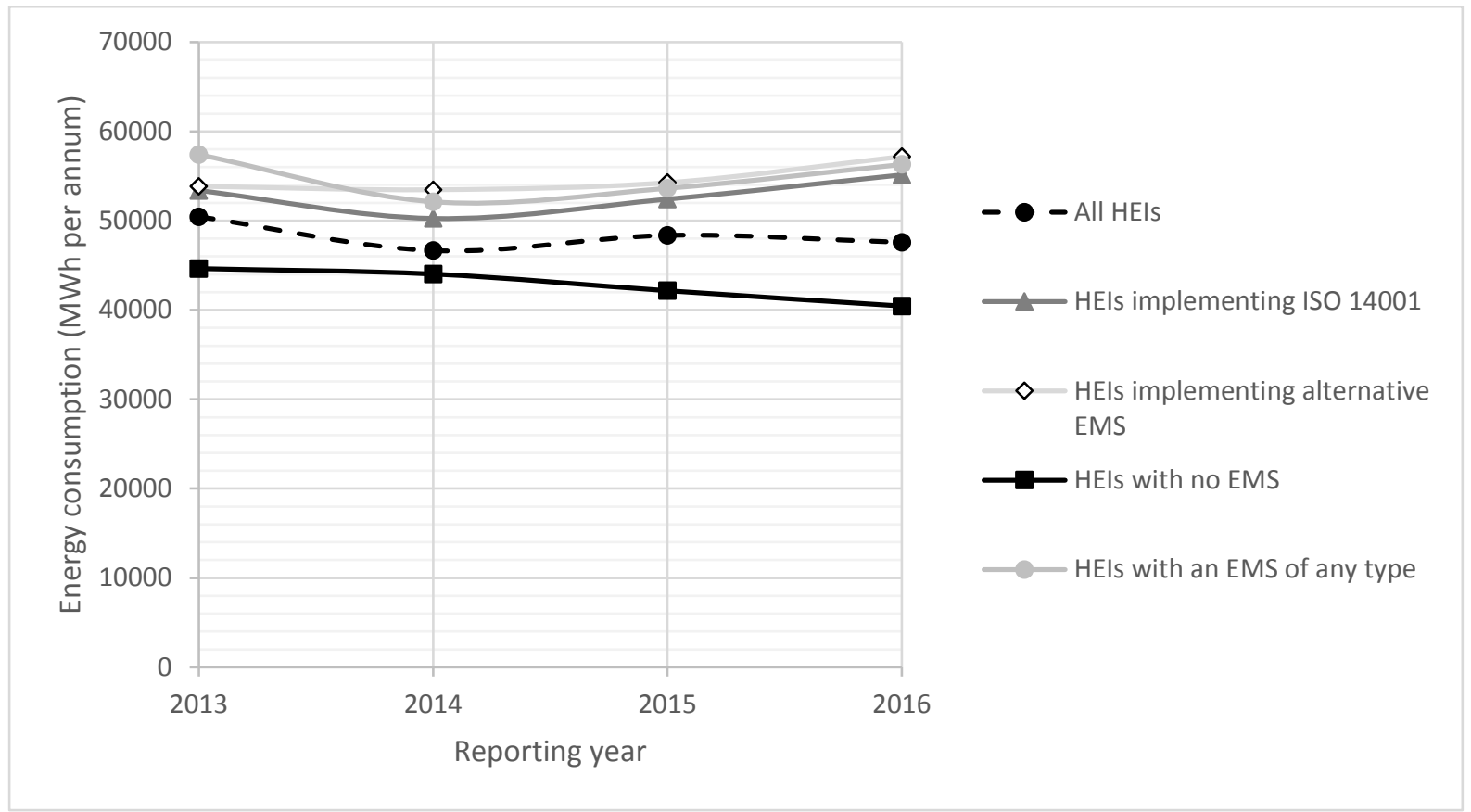

Figure 1. Average annual energy consumption (MWh) for HEIs reporting to HESA between $2012 / 13$ and $2015 / 16$ 


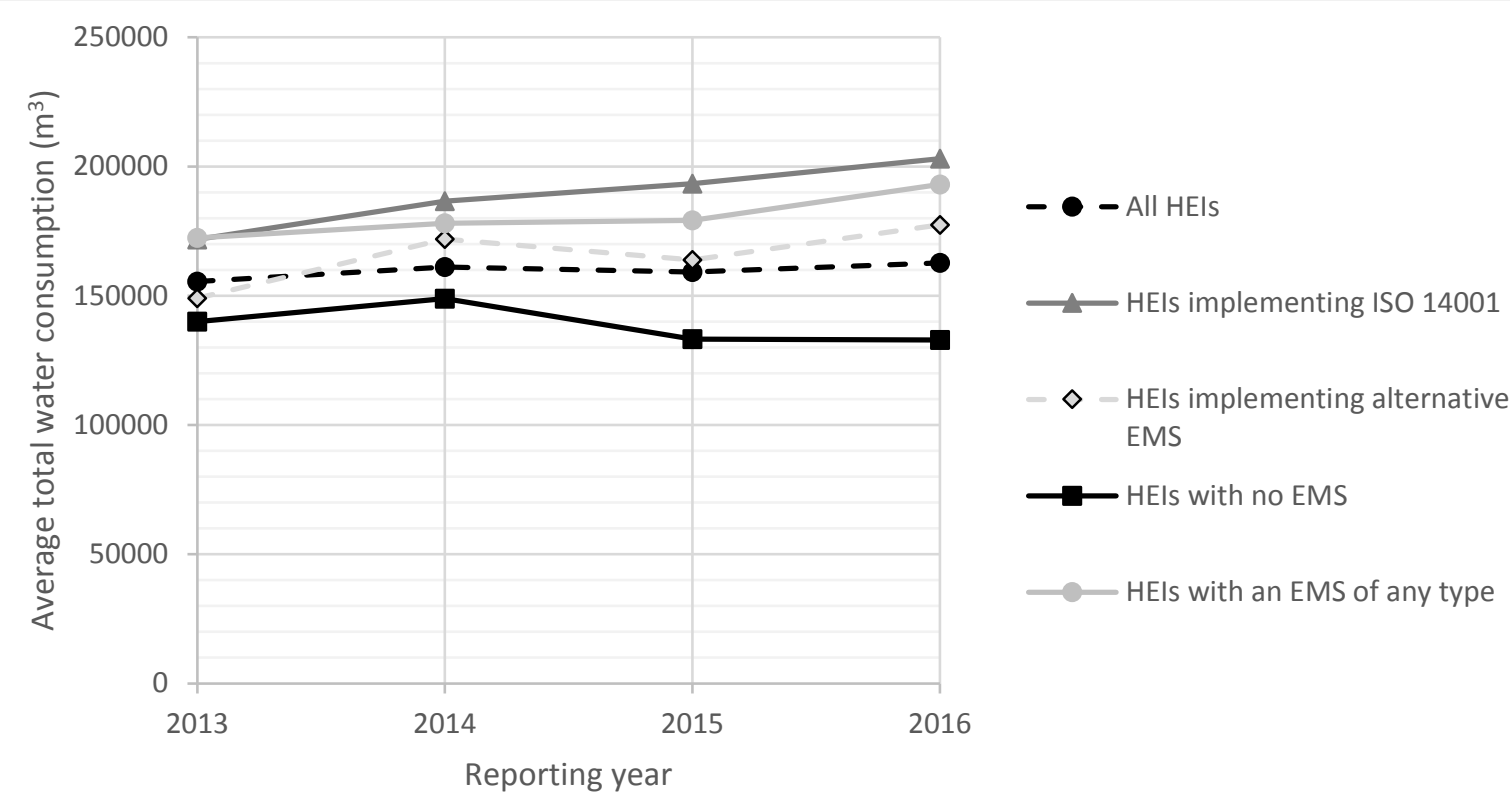

Figure 2. Average annual water consumption $\left(\mathrm{m}^{3}\right)$ for HEIs reporting to HESA between 2012/13 and 2015/16

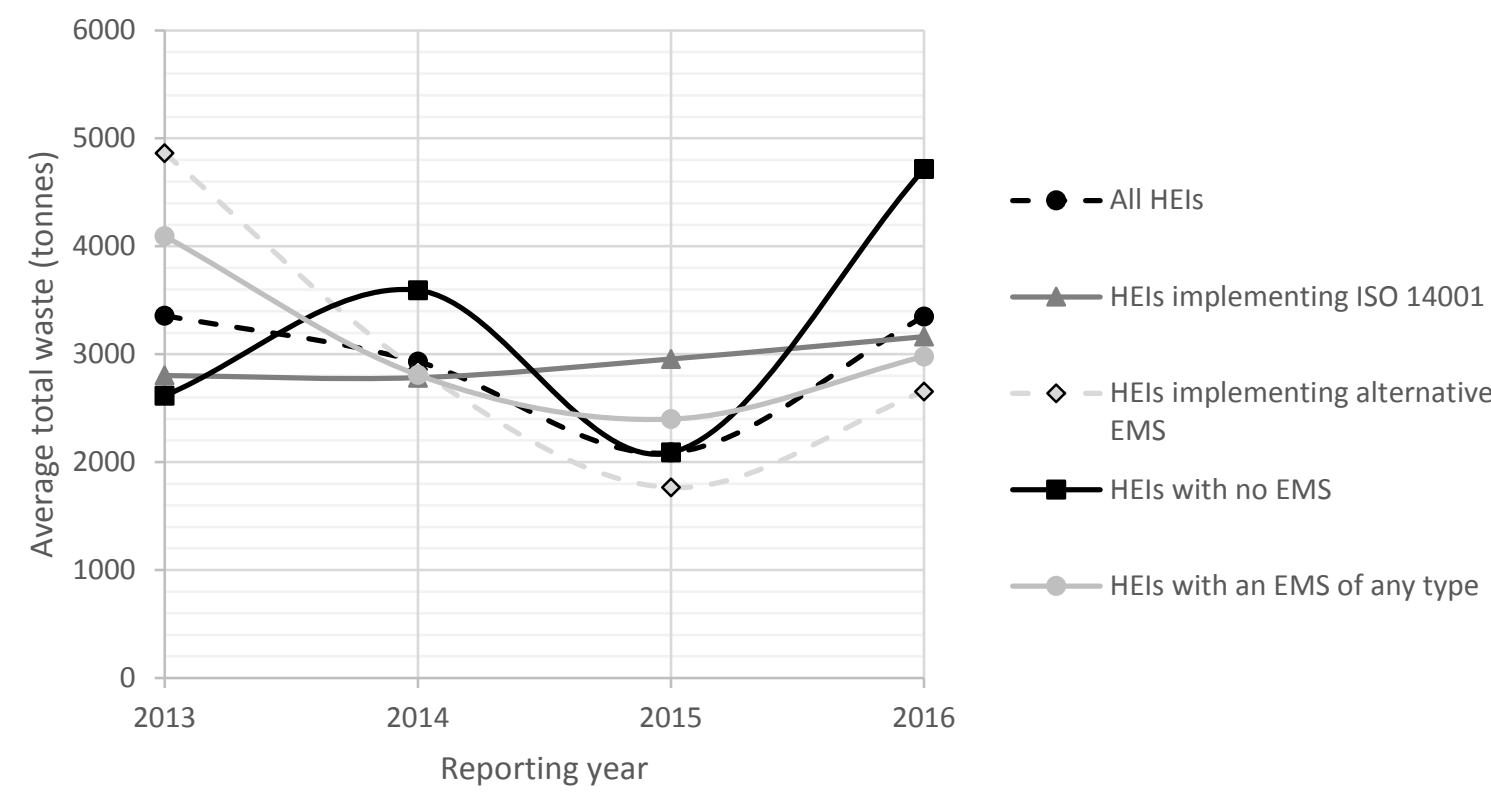

Figure 3. Average annual waste production (tonnes) for HEIs reporting to HESA between 2012/13 and 2015/16 
Fairtrade accreditation across HEls reporting to HESA 2013-2016

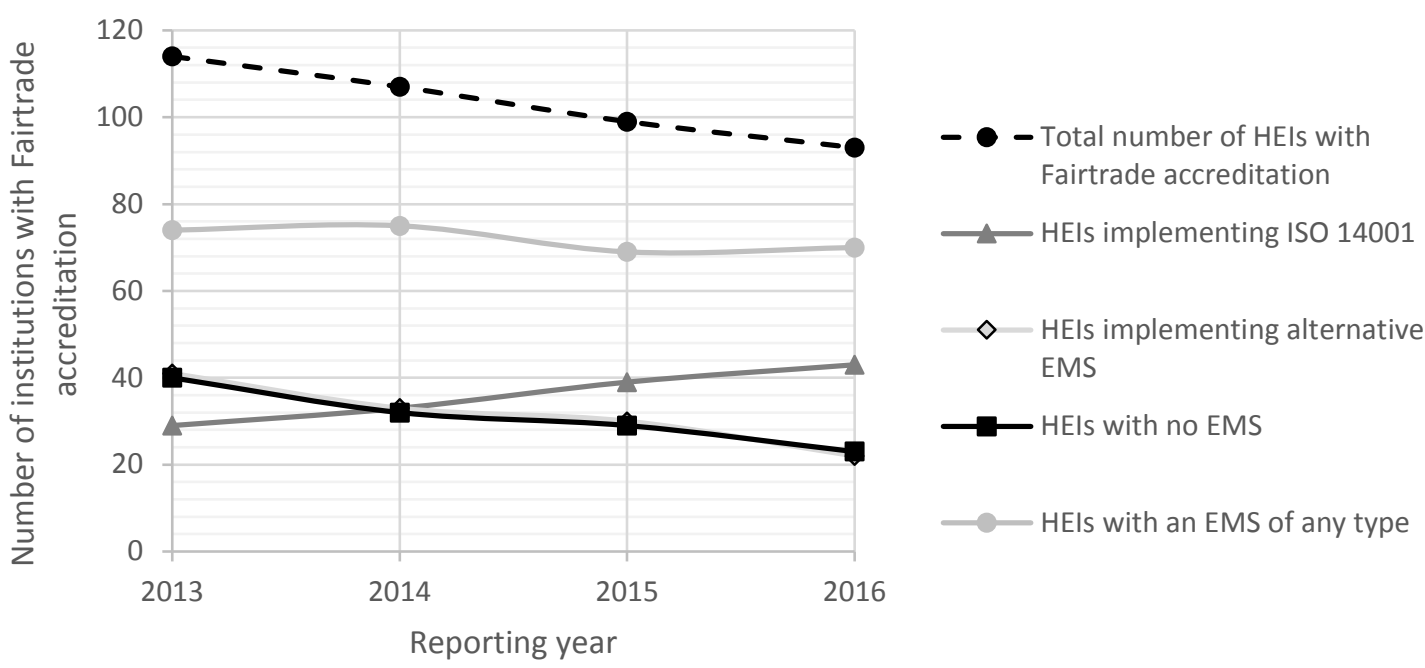

Figure 4. Number of HEIs reporting to HESA with Fair Trade accreditation 2012/13 to $2015 / 16$

In the area of resource consumption (Fig. 1, Fig. 2), HEIs with no EMS have on average lower energy and water consumption levels. As the figures are absolute and do not take account of use per person or other standardisation factor it is reasonable to deduce that this may be related to institution size, and overall student numbers. We observe that institutions implementing ISO 14001 have the largest number of both taught and research students (13531 and 724 full time equivalent (FTE) respectively, on average for 2015/16) compared to institutions with no EMS (7536 and 416 FTE respectively, on average for 2015/16). Typical management drivers for EMS implementation would suggest that institutions with larger levels of consumption, and hence greater costs associated with water and energy use are more driven to adopt systems to manage their resource consumption. However, not all large HEIs are implementing an EMS of any type, and some of the smallest institutions are implementing an ISO 14001 approach. An issue requiring further investigation is that resource consumption is increasing across organisations with an EMS compared to those with no EMS. Other factors may thus be driving the adoption of standards for these institutions, such as competition with other institutions on league tables (Green League), and reputation benefits of being seen to be "green".

Average waste production across the groups provides indicates fluctuations across the groups. Only the ISO 14001 group present a relatively steady average-waste-production profile compared to the other groups, with the group with no EMS displaying the greatest fluctuations in average-waste-production year on year. This may reflect the fact that measurement of waste production figures is more accurate and stable for institutions with systems, such as ISO 14001, in place to effectively measure and record waste production.

For the non-resource based metric (Fair Trade accreditation), there is a decrease in the total number of institutions with Fair Trade accreditation between 2013 and 2016. This appears to be matched by a decrease in the number of Fair Trade accreditations amongst HEIs with no EMS, and HEIs implementing alternative systems. In contrast, there is an increase amongst groups with ISO 14001. Part of this increase reflects HEIs with alternative systems transitioning to ISO 14001 accreditation (and taking their Fair Trade status with them). In fact, we see that organisations implementing an EMS of any type have only shown a slight decrease 
in numbers with Fair Trade accreditation. Most of the decrease is thus accommodated by HEIs with no EMS.

\subsection{Benchmarking performance}

While private sector organisations may use metrics such as turnover or number of employees to measure their baseline progress for various environmental indicators (e.g. energy or water consumption per employee), this is not as straightforward for HEIs. Benchmarking against other institutions using overall student numbers can be a misleading approach depending on the type and size of HEI, and distribution of students across disciplines. For example, the link between research activity, water and energy consumption for research student numbers shows a closer correlation as compared to overall student numbers (Altan, 2010; Marihno et al., 2013). The type of research conducted may also be important, with research within social sciences and the arts having a different demand on resources compared to science laboratory based research. Benchmarking is therefore a challenging area for HEIs in particular due to the lack of appropriate assessment frameworks and indicators available for evaluation and crosscomparison with other institutions. From one HEI to the next, the university population varies significantly based on factors such as the type of course offerings, the student numbers, the provision of student accommodation, facilities, and geographical location.

The wider reporting of environmental performance data in the Estates Management statistics in the UK is providing HEIs some ability to benchmark factors such as energy consumption and waste production against other institutions. However this provides only a simplistic comparison, which can be influenced by a number of factors. HEIs may benefit from identifying other ways to assess performance, such as partnership working with other HEIs to provide opportunities for shared learning. This approach is used in the Environmental Management System Implementation Model for U.S. Colleges and Universities (Savely, Carson, \& Delclos, 2007), where the value of third party auditing without the expense involved for systems seeking ISO 14001 is through working with other institutions providing flexibility and the opportunity for shared learning and benchmarking between institutions. This approach does not fit with formalised EMS approaches, where external auditing is a requirement, and opportunities for benchmarking and best-practice sharing are limited.

As the ISO14001:2015 standard moves towards closer alignment with the EMAS system, and incorporation of new criteria, it is unknown whether HEIs will still work towards achieving the more difficult standard, or seek to design a new standard for the sector. Recently, the case for implementation of formal systems such as EMAS in HEIs in Europe has been made (Torregrosa-López, Lo-Iacono-Ferreira, Martí-Barranco, \& Bellver-Navarro, 2016), although recognising that specific barriers are present for HEIs in this context. Observation over the transition period should detect whether HEIs with ISO14001:2004 accreditation are able to adopt the requirements of the new standard or whether they transition back to the alternative schemes such as Eco-Campus or bespoke systems.

\subsection{HEIs, EMS and organisational factors}

Environmental management amongst HEIs works better where objective and target setting takes account of HEI-specific organisational factors, and establishes useful metrics or performance indicators that can reflect true progress against a defined baseline as well as addressing some of the wider objectives and non-tangible measures related to widening 
awareness and adoption of sustainability principles across the organisation and society at large. Strategic conflicts may arise in setting performance indicators; for example, energy reduction targets, which may not be achievable where growth in specific areas of research activity suddenly leads to direct and unavoidable use of energy. In some institutions across the world, student places available across disciplines may be affected by strategic or political priorities identified by the funding body, thereby potentially affecting the make-up of the student population, and resource demand within HEIs. Providing non-indicator based or narrative assessments may be more appropriate in some cases, but can be less effective than indicator based reports and targets, and do not fit into formalised management systems (Lozano, 2006a; Disterheft et al., 2012). This may be more appropriate where fixed indicators are difficult to define or measure or where values fluctuate depending on specific on-campus activities. In using formal EMS approaches, defining non-standard indicators can conflict with the formal measurement and auditing requirements. This may be an area where HEI approaches to EMS may work better if they divert from standard formalised approaches. However, the review of UK HEIs shows a trend towards formal approaches, and emphasis of features such as resource management. This signals a more corporate approach to environmental management, that may leave some groups within HEIs disconnected from the process, and unable to pursue less measurable sustainability goals.

\section{Conclusions}

Many organisation characteristics affect the successful implementation of EMSs in HEIs. These include the organisational profile and key actor groups that will be involved, coordination of the system and organisational structure, governance and leadership structures, the ability of the organisation to deal with change, and the ability to recognise organisational barriers specific to HEIs. Middle-out approaches may be the most successful, but require strong support from the top in the form of resources and leadership, and support from the bottom in the form of enthusiasm, creativity and awareness-raising. Successful systems also require a designated environmental coordinator or manager, without which there is a high risk of failure. Linked to this, effective governance and leadership are needed to keep the system on track, with unambiguous roles and responsibilities and a clearly defined decision making structure. All organisations will experience some resistance to change, but being able to manage this effectively can enhance the benefits of EMS implementation, by helping to change behaviours and attitudes, and embed a culture of sustainability into an institution. A key point to consider is the recognition that different groups will respond to change in different ways. Approaches to EMS implementation should include increasing awareness and visibility, communication and clarity on what is being introduced and allowing interested actors to participate, recognising and celebrating efforts and successes. Encouragement to collaborate and get involved in decision making, and helping to make change easier by incorporating new features into existing systems can help reduce resistance. There is also a need to maintain management interest, by translating environmental and sustainability achievements into measurable indicators related to business benefits and communicate these widely.

The features discussed, may not be conducive to formal approaches, where strict controls, and defined management structures exclude participation across the institution towards change. There is a risk of poor integration where systems are delivered solely by estates and operations functions, without cross-university engagement and involvement limiting the ability to create meaningful impact and sustained change. The type of EMS implemented within an HEI favours less formalised systems, especially where a strong environmental policy and mechanisms for 
its implementation exist. Despite this, the increase in the number of UK HEIs implementing an ISO 14001 style EMS signals a shift towards formal managerial and operations led environmental management, away from systems that encourage a wider consideration of sustainability across key actor groups. Despite league tables such as the Green League identifying formal systems as the gold-standard of environmental management, formal approaches may only be suitable for HEIs where operations based environmental risks are significant, where resources are available, and where stakeholders or league tables are driving the requirement for certification. The HEI sector may benefit from establishing their own gold standard approach that, while prioritising improved environmental compliance, more widely addresses the inclusion of environmental and sustainability concerns in decision making across campus and integrating environmental values across all key actor groups, leading to long-term culture change and embedding of sustainability across society.

\section{References}

Aaltonen, P., \& Ikävalko, H. (2002). Implementing strategies successfully. Integrated Manufacturing Systems, 13(6), 415 - 418.

Altan, H. (2010). Energy efficiency interventions in UK higher education institutions. Energy Policy, 38, 7722-7731.

Bekessy, S. A., Samson, K., \& Clarkson, R. E. (2007). The failure of non-binding declarations to achieve university sustainability. A need for accountability. International Journal of Sustainability in Higher Education, 8(3), 301-316.

Beringer, A. (2007). The Luneberg Sustainable University Project in international comparison. An assessment against North American peers. International Journal of Sustainability in Higher Education, 8(4), 446-461.

Bero, B., Doerry, E., Middleton, R., \& Meinhardt, C. (2012). Challenges in the development of environmental management systems on the modern university campus. International Journal of Sustainability in Higher Education, 13(2), 133-149.

Bracke, R., \& Albrecht, J. (2007). Competing environmental management standards: how ISO 14001 outnumbered EMAS in Germany, the UK, France, and Sweden. Environment and planning C: government and policy, 25(4), 611-627.

Brinkhurst, M., Rose, P., Maurice, G., \& Ackerman, J. D. (2011). Achieving campus sustainability: top-down, bottom-up, or neither?. International Journal of Sustainability in Higher Education, 12(4), 338-354.

Button, C. E. (2008). Towards carbon neutrality and environmental sustainability at CCSU. International Journal of Sustainability in Higher Education, 10(3), 279-286.

Carpenter, D., \& Meehan, B. (2002). Mainstreaming environmental management. Case studies from Australasian Universities. International Journal of Sustainability in Higher Education, 3(1), 19-37.

Clarke, A., \& Kouri, R. (2009). Choosing an appropriate university or college environmental management system. Journal of Cleaner Production, 17, 971-984.

Disterheft, A., Caeiro, S. Ramos, M., \& Azeiteiro, U. (2012). Environmental Management Systems (EMS) implementation processes and practices in European higher education institutions. Top-down versus participatory approaches. Journal of Cleaner Production, 31, 80-90.

Esquer-Peralta, J., Velazquez, J. L., \& Munguia, N. (2008). Perceptions of core elements for sustainability management systems (SMS). Management Decision, 46(7), 1027-1038.

European Commission (EC) (2014). Eco-Management and Audit Scheme, available at: http://ec.europa.eu/environment/emas/register/ (accessed 07 June 2017). 
European Commission (EC) (2013). European Social Statistics 2013 Edition, Publications Office of the European Union, Luxembourg.

Higher Education Statistics Agency (HESA) (2017a). Estates Management Record 2015/16, available at: https://www.hesa.ac.uk/data-andanalysis/providers/overviews?year $=620 \&$ topic $\% 5 \mathrm{~B} \% 5 \mathrm{D}=605$ (accessed 12 June 2017).

Higher Education Statistics Agency (HESA) (2017b). Estates Management Record 2014/15, available at: https://www.hesa.ac.uk/data-andanalysis/providers/overviews?year=2\&topic $\% 5 B \% 5 \mathrm{D}=605$ (accessed 12 June 2017).

Higher Education Statistics Agency (HESA) (2017c). Estates Management Record 2013/14, available at: https://www.hesa.ac.uk/data-andanalysis/providers/overviews?year=3\&topic $\% 5 B \% 5 \mathrm{D}=605$ (accessed 12 June 2017).

Higher Education Statistics Agency (HESA) (2017d). Estates Management Record 2013/14, available at: https://www.hesa.ac.uk/data-andanalysis/providers/overviews?year $=9 \&$ topic $\% 5 \mathrm{~B} \% 5 \mathrm{D}=605$ (accessed 12 June 2017).

International Organization for Standardization (ISO) (2015). The ISO Survey of Management System Standard Certifications 2015, available at: https://www.iso.org/the-isosurvey.html (accessed 07 June 2017).

Jones, D. (2012). Looking through the greenwashing glass cage of the green league table towards the sustainability challenge for UK universities. Journal of Organizational Change Management, 25(4), 630-647.

Lozano, R. (2006a). A tool for a Graphical Assessment of Sustainability in Universities (GASU). Journal of Cleaner Production, 14, 963-972.

Lozano, R. (2006b). Incorporation and institutionalization of SD into universities: breaking through barriers to change. Journal of Cleaner Production, 14, 787-796.

Marinho, M., Gonçalves, M., \& Kiperstok, A. (2014). Water conservation as a tool to support sustainable practices in a Brazilian public university. Journal of Cleaner Production, 62, 98-106.

Nawrocka, D., \& Parker, T. (2009). Finding the connection: environmental management systems and environmental performance. Journal of Cleaner Production, 17(6), 601607.

NIEA (2009). Measuring the effectiveness of Environmental Management Systems Phase 2: Final Report Including Data \& Statistical Analysis. Northern Ireland Environment Agency, Belfast.

Ortas, E., Burritt, R., \& Moneva, J. M. (2013). Socially Responsible Investment and cleaner production in the Asia Pacific: does it pay to be good?. Journal of Cleaner Production, $52,272-280$.

Oung, K. (2013). Energy management in business, Ashgate Publishing, ebook, available at: http://www.ashgate.com/isbn/9781409452461 (last accessed 26 July 2017).

Palmer, B. (2004). Overcoming resistance to change. Quality Progress, 37(4), 35-39.

People and Planet. Environmental Auditing and Management Systems 2016. available at:

https://old.peopleandplanet.org/university-league/methodology-2016/3-environmental-auditsems (accessed 14 Mar 2017).

Psomas, E. L., Fotopoulos, C. V., \& Kafetzopoulos, D. P. (2011). Motives, difficulties and benefits in implementing the ISO 14001 Environmental Management System. Management of Environmental Quality: An International Journal, 22(4), 502521.

Rocha, M., Searcy, C., \& Karapetrovic, S. (2007). Integrating Sustainable Development into Existing Management Systems. Total Quality Management, 18(1-2), 83-92. 
Saleh, A., Kamarulzaman, N., Hashim, H., \& Hashim, S. (2011). An Approach to Facilities Management (FM) Practices in Higher Learning Institutions to Attain a Sustainable Campus (Case Study: University Technology Mara-UiTM). Procedia Engineering, 20, $269-278$.

Sambasivan, M., \& Fei, N. Y. (2008). Evaluation of critical success factors of implementation of ISO 14001 using analytic hierarchy process (AHP): a case study from Malaysia. Journal of Cleaner Production, 16(13), 1424-1433.

Savely, S., Carson, A., \& Delclos, G. (2007). An environmental management system implementation model for U.S. colleges and universities. Journal of Cleaner Production, (15), 660-670.

Spellerberg, I. Buchan, F., \& Englefield, R. (2004). Need a university adopt a formal environmental management system? Progress without an EMS at a small university. International Journal of Sustainability in Higher Education, 5(2), 125-132.

Spira, F., Tappeser, V., \& Meyer, A. (2013). Perspectives on Sustainability Governance from Universities in the USA, UK, and Germany: How do Change Agents Employ Different Tools to Alter Organizational Cultures and Structures? In: Caeiro. S., Filho, W., Jabbour, C. and Azeiteiro, U. (Eds.). Sustainability Assessment Tools in Higher Education Institutions, Springer, London, 175-188.

Spirovski, D., Abazi, A., Iljazi, I. Ismaili, M., Cassulo, G., \& Venturin, A. (2012). Realization of a low emission university campus through the implementation of a climate action plan. Procedia - Social and Behavioral Sciences, 46, 4695-4702.

Szyszja, B., \& Matuszak-Flejszmann, A. (2015). EMAS: Unfulfilled expectations and challenges associated with the planned publication of the new ISO14001:2015. WIT Transactions on The Built Environment, 168, 313-323.

Testa, F., Rizzi, F., Daddi, T., Gusmerotti, N. M., Frey, M., \& Iraldo, F. (2014). EMAS and ISO 14001: the differences in effectively improving environmental performance. Journal of Cleaner Production, 68, 165-173.

Tinsley, S. (2012). Environmental Management Systems: Understanding Organizational Drivers and Barriers. Taylor \& Francis, ebook, available at: http://abertay.eblib.com/patron/FullRecord.aspx?p=430033 (accessed 28 October 2015).

Torregrosa-López, J. I., Lo-Iacono-Ferreira, V., Martí-Barranco, C., \& Bellver-Navarro, C. G. (2016). The strengths of EMAS as an environmental management system for European university campuses. International Journal of Environment and Sustainable Development, 15(1), 89-106.

University Leaders for a Sustainable Future (ULSF) (2014). The Talloires declaration, available at: http://www.ulsf.org/programs talloires td.html (accessed 14 Mar 2014).

Wen-hsin Hsu, A., \& Wang, T. (2013). Does the market value corporate response to climate change?. Omega, 41, 195-206. 